\title{
What stops designers from designing sustainable packaging? - A review of eco-design tools with regard to packaging design
}

\author{
Xuezi Ma ${ }^{1,1}$ and James Moultrie ${ }^{1, *}$ \\ ${ }^{1}$ University of Cambridge, Department of Engineering, Institute for Manufacturing, Alan \\ Reece Building, 17 Charles Babbage Road, Cambridge, CB3 OFS, UK
}

\begin{abstract}
Packaging has caused much waste and its sustainability has received much attention in the past decades. Designers have made efforts to mitigate environmental impacts of packaging. However, many packaging designs are still far from achieving their sustainability goals. The purpose of this study is to perform a literature review of the principal design methods and tools for sustainable packaging published over the last twenty years. The objective is to understand the main obstacles that limit their effective implementation in the packaging design process. This study develops a sustainable packaging design and development model and proposes criteria for accessing packaging tools and methods. This study has found that to achieve sustainable design, many tools have limitations in demonstrating usage and balancing trade-off situations. Most of the tools focus on defining problems rather than suggesting possible solutions.
\end{abstract}

Keywords: Packaging; Eco-design; Tools; Sustainable production

\section{Introduction}

Packaging is not deemed useful after it has fulfilled its common purpose which is to protect and promote its product. As a result, packaging is considered a burden for the environment and a disrupting waste to the consumers (Verghese, 2005). Therefore in recent decades, packaging sustainability has received a lot of attention due to its major impact on the environment (Beitzen-heineke, 2015; Byggeth and Hochschorner, 2006). Consumers have increasingly taken products' sustainable performance into consideration while purchasing (Magnier and Schoormans, 2015; Hoogland et al., 2007). Due to increasing environmental consciousness, governments have launched standards and regulations to regulate green packaging.

Research into the environmental and economic impacts of packaging sustainability has been stimulated by regulations and market pressure. This research has produced a number of packaging sustainability guidelines, theories, strategies and tools. These have been made available to various stakeholders, including designers, engineers, technologists, marketers and environmental managers in the production, transportation and distribution areas of packaging production. However, it is argued 
that this proliferation of sustainability assessment methods and regulations has created confusion for packaging designers and other stakeholders (Slavin and Coordinator, 2016; Navarro et al., 2005). The available methods and tools may be inaccessible for designers to use in the design process. For example, designers may not know which tool applies better for different design stages, or they may get confused about what to expect from results of the tools and where to apply them. Furthermore, although organizations such as The Sustainable Packaging Alliance (SPA) in Australia, the Sustainable Packaging Coalition (SPC) in the US and The Industry Council for Research on Packaging and The Environment (INCPEN) in the UK have worked with brand owners, packaging companies and retailers to promote responsible packaging production, these research activities have established issues in packaging design, they have not managed to integrate packaging sustainability into packaging design and manufacturing decisions.

To access the usability of the eco-design tools, various literature reviews have been carried out. These are summarized in Table 1. The listed literature reviews are mainly focused on summarizing the generic methods in sustainable product design. Two of these reviews have looked explicitly at packaging as a critical issue, but none of them have discussed the usability of tools in packaging design. The packaging design process is a process balancing requirements such as protecting the content, promoting the product and fulfilling the transportation needs. Packaging design tools should help designers make choices between these requirements. Therefore tradeoff, as an important process during packaging design and development, should be specifically reviewed.

Table 1. Literature reviews.

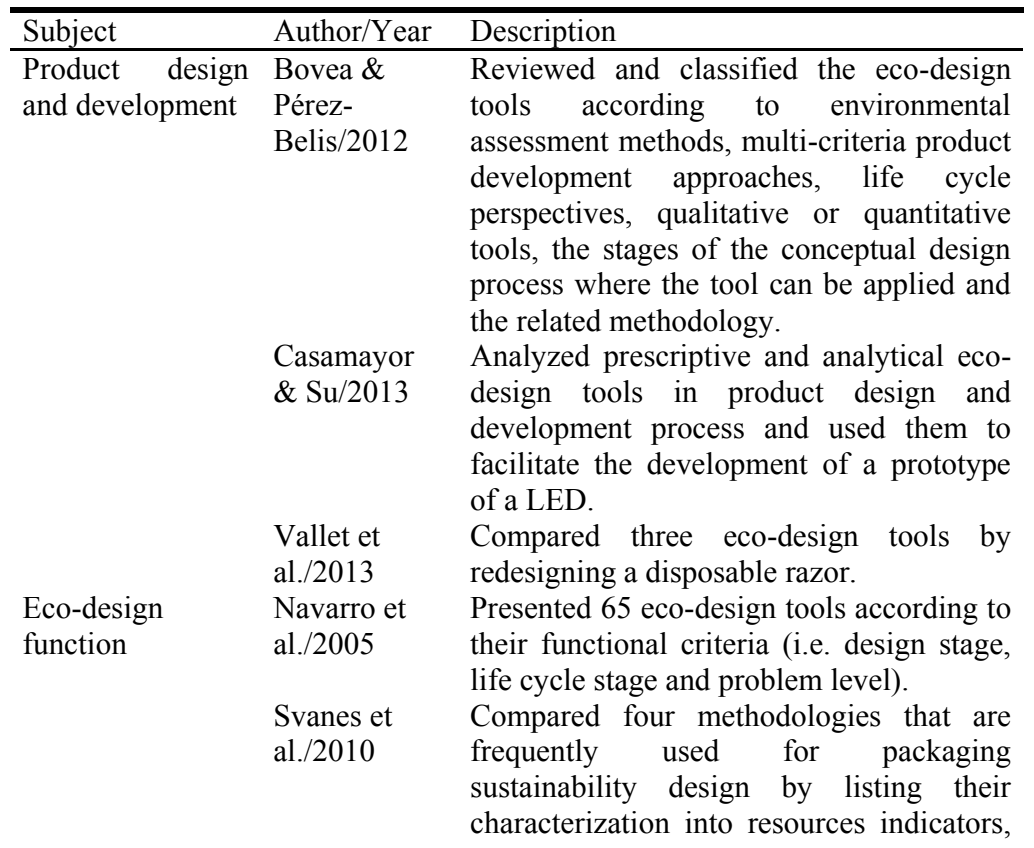


Trade-off situations

End-of-life strategies

Customer behavior market acceptance. $\mathrm{r} / 2006$

Rose/2000 Examined the existing end-of-life treatments, and presented an end-of-life model.

Niedderer et Reviewed the key theories, models and al./2014 approaches for behavior change in the sustainable design field.

To address the above mentioned issues, this study will review the existing sustainable packaging design tools and assess them from designers' perspectives, so that their usability can be evaluated in a structured manner to facilitate further packaging design research and activities.

This paper is structured as follows. Firstly, existing sustainable packaging design tools are reviewed and clustered according to the packaging design and development phases to which they can be applied. Next, results for these tools and the expected use for these results are discussed. This is followed by a discussion of whether these tools deal with trade off situations in the packaging design process. Lastly, the tools are analysed by their utility in facilitating packaging design. The paper concludes with opportunities for further research in this area.

\section{Method}

The review is covered from the perspective of three disciplines: packaging engineering, design and policy. Search terms differed slightly for the three perspectives owing to the different use of words among engineers, designers and policy researchers. For example, the term 'sustainable' gives a relatively large number of hits when searching a policy database, whereas the term 'environmental' is more effective when searching an engineering database (Baumann et al., 2002).

Sustainable packaging design literature was analyzed in the three steps described below:

- $\quad$ Search of six main databases (i.e. ScienceDirect, Google Scholar, Springer, ResearchGate, Wiley, Europe PMC) and screening the main references covering a time span of 20 years by scanning the abstract. Checking of references in the most important publications for additional references.

- Overview of the existing techniques for evaluating the environmental requirements of packaging in the references from the first step. Each method is briefly summarized.

- Review of tools that have been developed for improving packaging sustainability. Each tool is classified according to its methodology, measure and measurement. 
After analysing the literature, it is clear that there are few tools and methods focused on sustainable packaging design and development in the public domain. To analyse these tools from a designer's perspective, we selected tools and methods that are publicly accessible. Twelve tools and methods were found in the relevant packaging design and development field (Table 2). In the next section, the tools will be analysed according to their implementation phases in packaging design and development, their results and their usability of dealing with trade-off situations.

Table 2. Analyzed tools for sustainable packaging design and development.

\begin{tabular}{|c|c|c|}
\hline Tools & Author/Year & Description \\
\hline $\begin{array}{l}\text { Design } \\
\text { guidelines for } \\
\text { sustainable } \\
\text { packaging }\end{array}$ & $\begin{array}{l}\text { Sustainable } \\
\text { Packaging } \\
\text { Coalition/2006 }\end{array}$ & $\begin{array}{l}\text { Provides a framework for sustainable } \\
\text { packaging design while outlining various } \\
\text { design strategies and reference materials. }\end{array}$ \\
\hline & Aus & rs to \\
\hline Sust & Pacl & ging \\
\hline $\begin{array}{l}\text { Pack } \\
\text { Guid }\end{array}$ & $t / 2010$ & $\begin{array}{l}\text { to make efficient use of resources and } \\
\text { reduce environmental impact. }\end{array}$ \\
\hline Sust & Sust & Defines sustainable packaging in four \\
\hline Pack & $\mathrm{Pac}$ & dimensions: effective, efficient, cyclic and \\
\hline Fran & Alli & $\begin{array}{l}\text { safe. Gives the strategies for packaging } \\
\text { design, manufacture, logistic and } \\
\text { marketing in each dimension. }\end{array}$ \\
\hline Env & & Details the considerations needed to \\
\hline $\begin{array}{l}\text { Packaging } \\
\text { design for the } \\
\text { environment }\end{array}$ & 2008 & $\begin{array}{l}\text { develop pack systems that optimize use of } \\
\text { materials, energy and water and minimize } \\
\text { waste, and looks at the trade-offs between } \\
\text { different goals with the minimum } \\
\text { environmental impact. }\end{array}$ \\
\hline Sust & le & set of indica \\
\hline $\mathrm{P}_{9}$ & $\mathrm{Pe}$ & to use to \\
\hline $\begin{array}{l}\text { Indic } \\
\text { and } 1 \\
\text { Fram }\end{array}$ & $/ 2009$ & $\begin{array}{l}\text { progress toward the vision of sustainability } \\
\text { articulated in the SPC Definition of } \\
\text { Sustainable Packaging. }\end{array}$ \\
\hline Mat & $\begin{array}{l}\text { Ioultrie } \\
\text { Laura }\end{array}$ & $\begin{array}{l}\text { d grids to access the } \\
\text { aging design. }\end{array}$ \\
\hline $\begin{array}{l}\text { A Gui } \\
\text { Packa } \\
\text { Mater } \\
\text { Flows }\end{array}$ & de/2009 & for communication \\
\hline $\mathrm{Pacl}$ & le & of \\
\hline & & \\
\hline $\begin{array}{l}\text { Eva } \\
\text { Toc }\end{array}$ & 2006 & duct packaging systems \\
\hline & & the envi \\
\hline & & \\
\hline $\begin{array}{l}\text { Ratio Model } \\
\text { (EVR) }\end{array}$ & Vogtlä & $\begin{array}{l}\text { functionalities such as environmental } \\
\text { burden and marketing. }\end{array}$ \\
\hline
\end{tabular}




\begin{tabular}{lll}
$\begin{array}{l}\text { Packaging } \\
\text { Scorecard }\end{array}$ & $\begin{array}{l}\text { Carl Olsmats } \\
\text { Chris } \\
\text { Dominic/2003 }\end{array}$ & $\begin{array}{l}\text { Evaluates different criteria from supplier, } \\
\text { transportation, retailer and consumer's } \\
\text { perspectives. }\end{array}$ \\
COMPASS $/ 2009$ & $\begin{array}{l}\text { Assess packages on resource consumption, } \\
\text { emissions and packaging attributes. }\end{array}$ \\
SimaPro & Pre Sustainability & $\begin{array}{l}\text { Uses metrics to collect, analyze and } \\
\text { monitor the sustainability performance of } \\
\text { products } \\
\text { Evaluates product scenario by calculating } \\
\text { the environmental impacts }\end{array}$ \\
\hline
\end{tabular}

\section{Analysis of available tools in the packaging system}

Companies typically share the following steps in the product design and development phases: understanding the issue, exploring the possible solutions, defining and refining the solution, implementing the idea, manufacturing, distribution and sales (Waage, 2007; Poulikidou et al., 2014; Biju et al., 2015; Joore and Brezet, 2015). Compared to the normal product design and development phases, packaging design and development is proved to change due to its characteristics. Based on several packing development methodologies (Gordon, 1994; Griffin Jr, 1985; Brody, 1999; Paine, 1990; Buccia and Forcellini, 2007; Boylston, 2009a; Boylston, 2009b), the research in this paper proposes a Sustainable Packaging Design and Development Model. In general, it presents the packaging development process in three main phases: pre-development, development and post development. These three phases are broken into the following sub-processes: initial research, concept design, detail design, testing, packaging launch and packaging review. Note that the design stage begins after a period of comprehensive research. Along with the packaging development process, the applied stage of available sustainable packaging design tools for sustainable purpose is classified as follows:

1. Pre-development

- Initial research. Identifying the objectives of the product-packaging system that aligns with the company's policy and governments' regulations. Collecting information from internals (Production, Quality, Logistics, Retail environment, Marketing etc.) and externals (Competitive companies, Raw material and Packaging equipment suppliers).

2. Development

- Concept design. Proposing and selecting the most feasible ideas, economically, technically and environmentally (Design for X).

- Detail design. All levels of packaging are detailed. In this phase most of the activities run for packaging as well as product.

- Testing. Test packaging function as well as the market acceptance.

- Packaging launch. Including the planning, production and packing of the product and delivery to the sales point, and promoting packaging's environmental impacts.

3. Post-development 
- Packaging review. Keeping a record of the environmental performance of packaging, including its energy and water consumption, waste indicators, consumers' satisfaction and recycling process.

According to the packaging development process described above, the identified 12 methods and tools were clustered according to the three main applied stages described above for packaging design and development, with the corresponding qualitative and quantitative results (Table 3). It should be noted that only aids in sustainable packaging design have been included, although several tools exist to evaluate "sustainability". It is interesting that no quantitative tools have been found in the development phase. No qualitative tools have been found in the post-development phase. The following sections will look at how each tool could achieve its aim by analysing its functions along the packaging design and development process.

Table 3. Overview of sustainable packaging design tool.

\begin{tabular}{llll}
\hline & Pre-development & Development & Post-development \\
\hline Qualitative & Design guidelines for & A Guide to Packaging & \\
research & sustainable packaging & Material Flows and & \\
& Australian Sustainable & Terminology & \\
& Packaging Guideline & & \\
Sustainable Packaging & & \\
Framework & & \\
& Envirowise: Packaging & & \\
design for the environment & & Packaging \\
& Sustainable Packaging & & Scorecard \\
& Indicators and Metrics & & Life Cycle \\
& Framework & Inventory \\
Quantitative & Maturity Grid & & \\
\hline
\end{tabular}

\subsubsection{Pre-development}

Most of the listed tools can be applied at the pre-development stage. They include guidelines that are mainly developed by NGOs and governmental institutions such as SPC, SPA, Wrap and INCEPN. Guidelines like "Design guidelines for sustainable packaging" aim to help designers to understand the life cycle of sustainable packaging. During the life cycle of the packaging, these guidelines remind designers of the imperative design questions related to sustainable design during each packaging phase and also list the regulations and resources to refer to during the design of the corresponding stage. Similarly, "The Australian Sustainable Packaging Guideline" helps designers to reflect on their design by raising questions when they review the whole supply chain of designed packaging. Also, the Sustainable Packaging Framework defines sustainable packaging in four dimensions: effective, efficient, cyclic and safe. It gives generic strategies for packaging design, manufacture, 
logistics and marketing for each dimension, as well as the key performance indicators for these strategies.

Metrics and maturity grids are specified for sustainable packaging design. The Sustainable Packaging Indicators and Metrics Framework introduces indicators and metrics to help stakeholders to measure the sustainability of packaging (resource usage and waste produced) during the supply chain before production. It declares the different terms by giving definitions and explaining how to measure these items as well as why to measure them. (Moultrie et al., 2016) develops a maturity grid of sustainable packaging through interviews with practitioners from companies of different sizes. It selects different criteria to judge the sustainable performance of a package in different stages of a packaging's life cycle.

Based on Streamlined life cycle assessment, the Packaging Impact Quick Evaluation Tool (PIQET) has been developed to assess the sustainability of packaging by calculating the product/packaging ratio, environmental impact indicator, as well as analysing the inventory in each life cycle stage of packaging. Software such as COMPASS, SimaPro and GaBi make information accessible to non-LCA professionals to manage data and compare design concepts. Based on the LCA theory, (Wever and Vogtländer, 2013) developed the Eco-Costs/Value Ratio Model (EVR Model), which can be used to compare the eco-burden of a packaging with the value created.

\subsubsection{Development}

A Guide to Packaging Material Flows and Terminology creates a close loop material system for nine major packaging materials. These unified terms are used across stakeholders.

\subsubsection{Post-development}

The packaging scorecard method is used to evaluate different criteria like handleability, flow information, product protection, volume and weight efficiency from supplier, transportation, retailer and consumer perspectives. It scores each criterion so that companies can work towards their own improvement.

\subsection{Looking at the results for sustainable design tools}

In qualitative tools, the results may simply be some yes or no answers of some sustainable design questions along the supply chain. The outcomes of qualitative tools, however, may not be sufficient because they could evaluate very different products with similar results. For example, in design guidelines for sustainable packaging, it is hard to make choices between two design concepts if they both satisfy the same conditions such as eliminating all necessary packaging components, 
optimizing a package's dimensions to best fit the product and considering the effect of using recycled material on a package's technical performance.

For quantitative tools, LCA based software such as PIQET, COMPASS, SimaPro and $\mathrm{GaBi}$ provides detailed life cycle environmental impacts of packaging life cycle phases such as the accurate amount of carbon dioxide. The Eco-Costs/Value Ratio Model defines the sustainability of packaging by calculating its eco-costs/value and comparing the relative location in the eco-costs and value diagram. The Packaging scorecard defines the problems in the packaging supply chain by providing scores for each phase. The Life Cycle Inventory qualifies the material use, energy use, environmental discharges and wastes associated with packaging life cycle phases, from raw material extraction to material processing, packaging fabrication, use, reuse or recycling, and ultimate disposal.

\subsection{Looking at how trade offs are incorporated}

Current research indicates that consumers' attention on environmentally friendly packaging have steadily increased during the past decades (Nordin and Selke, 2010; Martinho et al., 2015; Magnier and Schoormans, 2015; Lofthouse et al., 2009). The pressure of balancing trade-offs also comes from regulations. Nearly 200 European Union directives have been released to regulate the sustainability of packaging (Giancristofaro and Bordignon, 2016). Packaging in the whole system (primary, secondary and tertiary packaging) needs to be minimized without compromising its function of safety, protection and promotion. However, minimizing the packaging usage does not mean minimizing the environmental impacts. For example, if manufacturers reduce the packaging materials in primary packaging to save the raw materials and decrease the transport weight, the content may be damaged during the transportation, which causes a lager waste to the environment. To balance this situation, a valuation (e.g. rating of the importance of criteria or strategies within each tool) has to be included in the tool (Byggeth and Hochschorner, 2006). Based on this criterion, tools were classified in Table 4.

Table 4. Sustainable packaging tools classified according to whether they contain valuation.

\begin{tabular}{|c|c|c|c|}
\hline & Pre-development & Development & Post-development \\
\hline $\begin{array}{l}\text { Valuation in the } \\
\text { tools }\end{array}$ & $\begin{array}{l}\text { Design guidelines for } \\
\text { sustainable packaging } \\
\text { Australian Sustainable } \\
\text { Packaging Guideline } \\
\text { Sustainable Packaging } \\
\text { Framework } \\
\text { Envirowise: Packaging } \\
\text { design for the environment } \\
\text { Packaging Impact Quick } \\
\text { Evaluation Tool (PIQET) } \\
\text { COMPASS/SimaPro/GaBi }\end{array}$ & & $\begin{array}{l}\text { Packaging } \\
\text { Scorecard } \\
\text { Life Cycle } \\
\text { Inventory }\end{array}$ \\
\hline No valuation in & Eco-Costs/Value Ratio & A Guide to Packaging & \\
\hline
\end{tabular}


Guidelines such as Design Guidelines, Australian Sustainable Packaging Guidelines, Sustainable Packaging Framework and Envirowise offer strategies to facilitate designers' balance of possible consequences and sensible choices. LCA based tools such as PIQET, COMPASS, SimaPro and GaBi rate the importance of each environmental impact that the design concept may have by quantifying the facts (i.e. carbon dioxide emission, water waste, land waste, recyclate etc.). Tools with valuations are feasible for sustainable packaging design. Based on these analysis results, tools with valuation are picked and classified by criteria in the following subsection.

\subsubsection{Looking at how trade offs are incorporated}

To make the tools accessible and feasible for packaging designers to use in trade-off situations as well as to assist in picking a suitable design concept, they have to satisfy certain criteria. For example, in order to choose the suitable packaging concept tools designers need a list of important requirements for sustainable packaging solutions or the results of tools have to be meaningful with regard to developing sustainable packaging solutions. Also, some of the tools have other purpose, but we will not regard it as satisfying certain criteria if that is not its main purpose. Through reviewing the literature, criteria for aiding design sustainable packaging have been proposed as follows:

1. Whether the tool gives specific directions or generic guidance?

Design decisions vary due to different types of results for different tools. Specific directions give designers specific strategies to achieve certain sustainable goals, whereas generic guidance facilitates designers to identify crucial design issues. 2. Whether the tool takes the total packaging/product system into consideration?

The tool should take a holistic overview of the packaging/product system from the sustainable perspective. It should include indicators such as the mass of material that has been used, whether it has been recycled or not, the energy use along the supply chain, product waste and the degree filling for primary, secondary and tertiary packaging.

3. Whether the tool provides design alternatives?

Alternatives should be provided to demonstrate the "right" direction. Compared to abstract indicators, concrete examples are an easier reference to designers.

4. Whether the tool includes examples to illustrate its guidance?

Guidance should give examples to show how to fulfil the requirements in the instructed way.

5. Whether the tool demonstrates hierarchy for sustainable decisions in different aspects? 
Packaging design involves complicated trade-off situations. Designers have to balance requirements from companies, manufacturers and consumers as well as raw material extraction, distribution, marketing and recycling. It is impossible for designers to satisfy all requests. Tools should help designers to prioritise requirements in different situations.

6. Whether the tool considers the preservation of product quality?

The original aim for packaging is to protect its content from physical and chemical damages such as stacking pressure, moist, oxidization and toxicity. This helps designers avoid potential harm to the product.

$7 . \quad$ Whether the tool calculates the distribution cost?

Distribution costs include packaging material cost, packaging process cost, transportation cost, handling cost and product loss.

8. Whether the tool requires designers to have pre-knowledge or experience to use the tool?

Tools should be accessible for designers to an effectively and efficiently check their design innovations. Requesting pre-knowledge may cause barriers to designers with limited sustainable knowledge and training.

For the purpose of this reason, tools were screened based on the above criteria and the results are shown in Table 5. It is clear that none of the tools demonstrates hierarchy for sustainable decisions. This may cause confusion for designers when making design decisions. After defining the problems and issues, it would be difficult for designers to balance the environmental issues and decide which "less worse" decision to make. Also, none of the tools calculate the costs, which should be prioritized during the decision make process.

Table 5. Sustainable packaging tools analyzed according to whether tools fulfill the criteria.

\begin{tabular}{|c|c|c|c|c|c|c|c|c|}
\hline Tools & 1 & 2 & 3 & 4 & 5 & 6 & 7 & 8 \\
\hline $\begin{array}{l}\text { Design } \\
\text { guidelines for } \\
\text { sustainable } \\
\text { packaging }\end{array}$ & Generic & $\checkmark$ & & 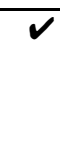 & & & $T$ & \\
\hline $\begin{array}{l}\text { Australian } \\
\text { Sustainable } \\
\text { Packaging } \\
\text { Guideline }\end{array}$ & Generic & $\checkmark$ & & $\checkmark$ & & & 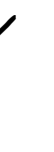 & \\
\hline $\begin{array}{l}\text { Sustainable } \\
\text { Packaging } \\
\text { Framework }\end{array}$ & Generic & $\checkmark$ & & $\checkmark$ & & & & \\
\hline $\begin{array}{l}\text { Envirowise: } \\
\text { Packaging } \\
\text { design for the } \\
\text { environment }\end{array}$ & Generic & $\checkmark$ & & $\checkmark$ & & & 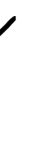 & \\
\hline $\begin{array}{l}\text { Packaging } \\
\text { Impact Quick } \\
\text { Evaluation } \\
\text { Tool (PIQET) }\end{array}$ & N.m. & $\boldsymbol{\nu}$ & & & & & & \\
\hline Packaging & Specific & $\checkmark$ & & & & & & \\
\hline
\end{tabular}




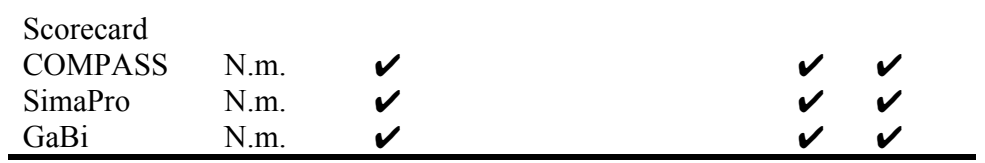

\section{Conclusion}

The design of packaging is not a priority in many companies. The complexity of packaging with regard to its varied life cycle and a relatively small market size limit the professionalism within this field. However, due to the growing environmental issues that packaging has caused, the sustainability of packaging has been pushed up the agenda. It seems that knowledge of the subject of packaging design is still fragmented and there is a need to tackle packaging design problems more structurally. The thorough analysis of literature on sustainable design tools and methods in the sustainable packaging design field confirms that despite the great number of approaches proposed by researchers in this field, designers still have difficulties in their practical and effective implementation and use. Tools are mainly focused on defining problems rather than giving solutions. For example, tools like PIQET and Design guidelines for sustainable packaging are keen on reminding designers of the environmental impacts by qualifying the waste or encouraging reflection on potential issues. Concrete suggestions and possible ways to refine the design, however, are missing. Together, the review results amount to saying that researchers in the packaging design and development field need to research existing tools in more depth to make them more usable as well as develop new tools to better address designers' real needs.

This paper reviewed existing eco-design tools in the packaging domain from a designer's perspective. Future work requires discussion with designers about the practical use of these tools as well as testing of the packaging framework and proposed criteria in a real life context to better understand how sustainable packaging design tools can best be implemented. It would be beneficial to collect designers' real needs for improving packaging sustainability through case studies.

Related to this, it is evident that in different firms there are complex trade-offs to be made between different elements through packaging design. Due to the complicated nature of packaging, how firms handle the trade-offs during sustainable packaging design might provide fruitful opportunities for research.

Finally, assessing the current eco-design methods is only part of the story. To be effective in the long term, changes to design processes and practices need to be more formally institutionalised. There is thus work to be done in better understanding how such changes can be implemented and good practices anchored as part of a company's design activity. 


\section{References}

Baumann, H., Boons, F. and Bragd, A. (2002), "Mapping the green product development field : engineering, policy and business perspectives", Vol. 10, pp. 409-425.

Beitzen-heineke, E.F. (2015), "The prospects of zero-packaging grocery stores to improve the social and environmental impacts of the food supply chain", Journal of Cleaner Production, Elsevier Ltd, No. September, pp. 2014-2015.

Biju, P.L., Shalij, P.R. and Prabhushankar, G. V. (2015), "Evaluation of customer requirements and sustainability requirements through the application of fuzzy analytic hierarchy process", Journal of Cleaner Production, Elsevier Ltd, Vol. 108, pp. 808-817.

Boylston, S. (2009a), Designing Sustainable Packaging, Laurence King Publishing.

Boylston, S. (2009b), Designing Sustainable Packaging, Laurence King Publishing.

Brody, A.L. (1999), "Development of packaging for food products", Developing New Food Products for a Changing Marketplace, pp. 313-351.

Buccia, D.Z. and Forcellini, F.A. (2007), "Sustainable Packaging Design Model”, Complex Systems Concurrent Engineering, Springer London, pp. 363-370.

Byggeth, S. and Hochschorner, E. (2006), "Handling trade-offs in Ecodesign tools for sustainable product development and procurement", Journal of Cleaner Production, Vol. 14 No. 15-16, pp. 1420-1430.

Gordon, W.F. (1994), New Food Product Development: From Concept to Marketplace, CRC Press.

Giancristofaro, R.A. and Bordignon, P. (2016), "Consumer preferences in food packaging: CUB models and conjoint analysis”, British Food Journal, Vol. 118 No. 3, pp. 527-540.

Griffin Jr, R. (1985), "Materials and package testing”, Principles of Package Development, Avi Publishing Company Inc., pp. 130-167.

Hoogland, C.T., de Boer, J. and Boersema, J.J. (2007), "Food and sustainability: do consumers recognize, understand and value on-package information on production standards?", Appetite, Vol. 49 No. 1, pp. 47-57.

Joore, P. and Brezet, H. (2015), “A Multilevel Design Model: the mutual relationship between product-service system development and societal change processes", Journal of Cleaner Production, Vol. 97, pp. 92-105.

Lofthouse, V.A., Bhamra, T.A. and Trimingham, R.L. (2009), "Investigating customer perceptions of refillable packaging and assessing business drivers and barriers to their use", Packaging Technology and Science, Vol. 22 No. 6, pp. 335-348.

Magnier, L. and Schoormans, J. (2015), "Consumer reactions to sustainable packaging: The interplay of visual appearance, verbal claim and environmental concern", Journal of Environmental Psychology, Elsevier Ltd, Vol. 44, pp. 53-62.

Martinho, G., Pires, A., Portela, G. and Fonseca, M. (2015), "Factors affecting consumers' choices concerning sustainable packaging during product purchase and recycling", Resources, Conservation and Recycling, Vol. 103, pp. 58-68.

Moultrie, J., Sutcliffe, L. and Maier, A. (2016), "A maturity grid assessment tool for environmentally conscious design in the medical device industry", Journal of Cleaner Production, Vol. 122, pp. 252-265.

Navarro, G., Rizo, Tc., Ceca, Sb. and Collado Ruiz, M.J. (2005), "Ecodesign Function and Form. Classification of Ecodesign Tools According to Their Functional Aspects", ICED 05: 15th International Conference on Engineering Design: Engineering Design and the Global Economy, Vol. 12 No. 5, p. 3839.

Nordin, N. and Selke, S. (2010), "Social aspect of sustainable packaging", Packaging Technology and Science, Vol. 23 No. 6, pp. 317-326.

Paine, F.A. (1990), Packaging Design and Performance, Pira.

Poulikidou, S., Björklund, A. and Tyskeng, S. (2014), "Empirical study on integration of environmental aspects into product development: Processes, requirements and the use of tools 
in vehicle manufacturing companies in Sweden”, Journal of Cleaner Production, Vol. 81, pp. 34-45.

Slavin, B.C. and Coordinator, S. (2016). "How to Assess Sustainable Packaging: An Overview of The Tools and Resources Available", available at: http://leadwise.mediadroit.com/files/18826HowtoAssessSusPkgfordistribution.pdf (accessed 26 November 2016).

Verghese, K. (2005), "Sustainable packaging: how do we define and measure it", 22nd IAPRI Symposium, ResearchGate, Australia.

Waage, S.A. (2007), “Re-considering product design: a practical 'road-map' for integration of sustainability issues", Journal of Cleaner Production, Vol. 15 No. 7, pp. 638-649.

Wever, R. and Vogtländer, J. (2013), "Eco-efficient Value Creation: An Alternative Perspective on Packaging and Sustainability", Packaging Technology and Science, Vol. 26 No. 4, pp. 229-248.

\section{Review 1}

Well done, this is a well structured piece of research.

Thank you for your kind works.

I suggest that you add a paragraph to your conclusion that suggests directions for further research based on your findings. Research builds on research and you have detailed the 'state of the problem' but where to from here?

Thank you for this observation. We have added an additional paragraph to the conclusion, which hopefully strengths the case for future research.

\section{Review 2}

What stops designers from designing sustainable packaging??A review of ecodesign tools with regard to packaging design

The proposed paper presents a review of eco-design tools with regard to packaging design. The paper is well written and it is suitable to be accepted for KESSDM-2017 conference after two minimal revisions. In particular the authors have to consider the following considerations and suggestions:

1. In page 3 row 19: ?three steps? instead of ?four steps?. Yes, you are correct, this has been changed.

2. As regards table 5 in my opinion the tool Simapro provides design alternatives through the function of comparative analysis. I don't know the same information about the other tools. I suggest to the authors to verify all the information of Table 5. 
Thank you for mentioning this. Some of the tools may also have other purpose, but we think that's not its main purpose for sustainable packaging. We have emphasized this in the paper. 